\title{
Grabados y pinturas del arte rupestre tardío de Caspana ${ }^{1}$
}

\author{
Flora Vilches V. ${ }^{2}$ Y MaURicio URIbe R. ${ }^{3}$
}

\section{RESUMEN}

Este es un estudio exploratorio que trata el problema del Inca en la cuenca superior del río Loa a través del arte rupestre detectado en varios sitios del Período Tardío de Caspana, con singular referencia a las expresiones presentes o asociadas a las instalaciones incaicas. De este modo, se define una iconografía que sería propia del Horizonte Tardío y que tendría connotaciones especialmente simbólicas en las estrategias del Tawantinsuyu para relacionarse con la población local.

\begin{abstract}
This is a exploratory study about the Inca problematic in the upper basin of the Loa river base on rupestrine art detected in some Late Period sites of Caspana, with singular reference to the expressions present or asociate at inca installations. In this way, it define a Late Horizon iconografy, with simbolic connotations for the Tawantinsuyu strategies to relate with local people.
\end{abstract}

\section{Introducción}

En Caspana se registraron 38 paneles de arte rupestre distribuidos en ocho sitios comprendidos por los sectores Talikuna, Cerro Verde, Caspana, Incahuasi-Inca y Vega Salada, los cuales fueron fichados, fotografiados y algunos de ellos releva-

Proyectos FONDECYT 1970528 y 1000148.

2 Department of Art History and Archaeology University of Maryland College Park. Email: fvilches@wam.umd.edu

3 Departamento de Antropología de la Facultad de Ciencias Sociales de la Universidad de Chile. Email: mur_cl@yahoo.com dos a través de dibujos a escala.

Dicho registro fue realizado con el propósito de entender desde la dimensión de este "arte" la expansión del Tawantinsuyu a la cuenca superior del río Loa y, de este modo, complementar la información arrojada por el resto de los estudios realizados en la localidad de Caspana, con el subsecuente objetivo de concebir las posibles estrategias de conquista, dominio e integración de su población gracias a su considerable potencial simbólico. En cualquier caso, éste corresponde a un primer acercamiento al tema y debe considerarse como tal (Vilches 1999).

\section{Los sitios y sus manifestaciones}

En Aldea Talikuna se realizó una detallada y reiterativa revisión del asentamiento como de los sectores aledaños que permitió contabilizar seis paneles o unidades de relevamiento de arte rupestre sólo en el asentamiento mismo. Todos se ubican al interior de la aldea y corresponden a grabados localizados en bloques menores que forman parte de los muros estructurales de recintos y, en el menor de los casos, en piedras móviles empleadas en vías de circulación (Figuras 1a y 1b). La totalidad de ellos se localiza en el sector medio del asentamiento con una distribución espacial relativamente homogénea. Las representaciones rupestres corresponden íntegramente a grabados ejecutados en su mayoría por percusión y sustracción profunda del soporte rocoso.

El caso más extremo de esta situación corresponde a un bloque aislado de considerable tamaño, ubicado entre la aldea y los andenes que se hallan 


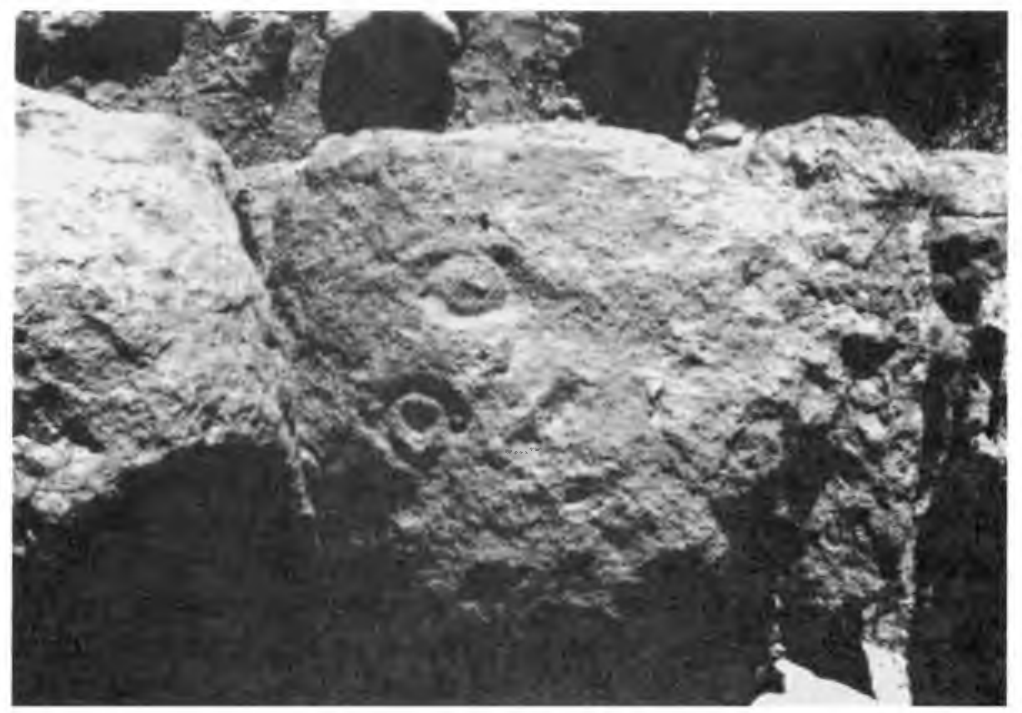

Figura la. Grabado de diseño geométrico correspondiente a dos círculos concéntricos

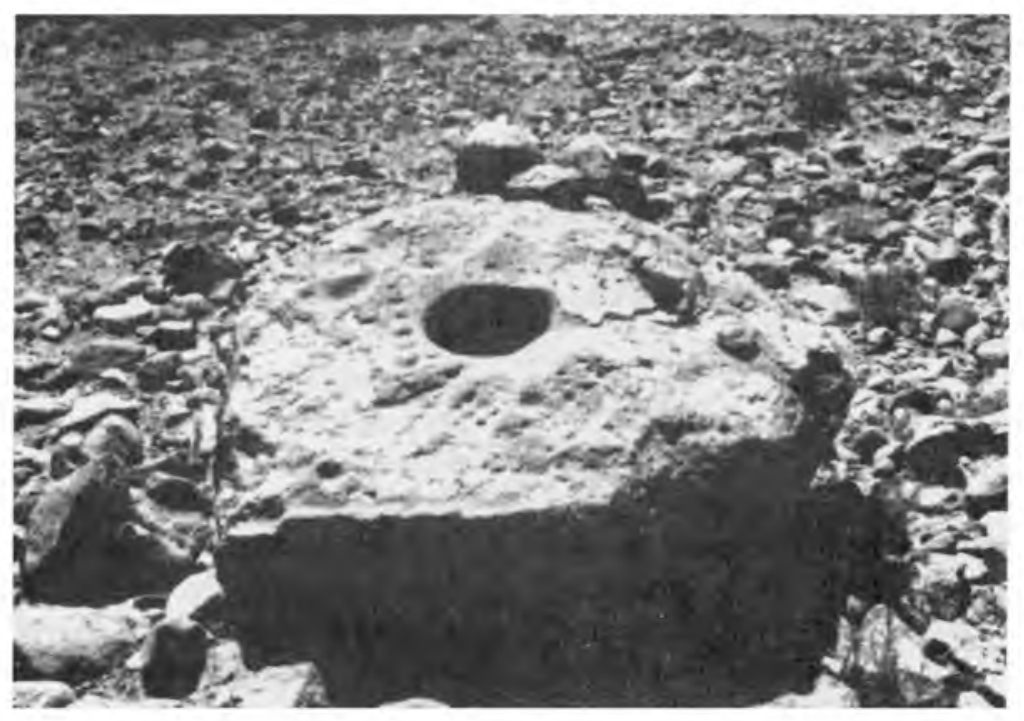

Figura 1b. Bloque aislado que presenta una horadación o "tacita" en cuyo alrededor se distribuyen conjuntos de agujeros más pequeños 
a sus pies, el cual sobre su cara superficial presenta una horadación o "tacita" y trazas de evidente pulido de la roca, en cuyo alrededor se distribuyen conjuntos de agujeros más pequeños en diámetro y profundidad, pero dispuestos de manera no aleatoria (p.e. en hileras, en series pareadas, etc.) (Figura 1b). Quizás la tacita es la única expresión que podría tener ribetes más funcionales que decorativos, por ejemplo para actividades de molienda, sin embargo, las series de agujeros que la circundan hacen pensar en usos y/o significados estéticos complementarios.

Los paneles restantes, por su parte, coinciden en presentar líneas verticales o ligeramente curvas de surco delgado y profundo obtenido por percusión, diseño que también aparece en algunos soportes del Pukara de Turi (Gallardo y Vilches 1995). No obstante, en Talikuna uno de ellos aunque se basa en la misma técnica, presenta un diseño diferente, claramente geométrico, correspondiente a dos círculos concéntricos, uno en positivo y el otro en negativo, como resultado de una "sustracción por oposición" de sus respectivos elementos compositivos (Figura 1a). Después del primero mencionado, este panel es el más figurativo del sitio y formalmente podría asemejarse, con ciertas reservas, a la variante "espiral" de Turi (Gallardo y Vilches 1995).

Ahora bien, la ausencia de una instalación incaica propiamente tal en el asentamiento y los correlatos con el Pukara de Turi, sugieren que este tipo de arte corresponde más bien a manifestaciones desarrolladas por grupos locales durante los Períodos Intermedio Tardío y Tardío. Esta situación se extendería hasta el Salar de Atacama como lo demuestran las manifestaciones de esta clase en la Aldea Zapar, correspondiente a la misma época y asignación cultural (Le Paige 1958).

En cambio, aproximadamente a unos $150 \mathrm{~m}$ al sur de la instalación inca de Cerro Verde se localiza un pequeño afloramiento aislado de ignimbritas que albergan tres paneles de arte rupestre, desde donde se visualiza directamente el ushnu de aquel sitio, ubicado hacia el norte. Las representaciones son en su totalidad grabados, la mayoría camélidos rígidos construidos por líneas simples y/o por raspado de superficies mayores. Algunos de ellos, incluso, presentan pintura ocre rellenando aque- llas áreas raspadas. Otro rasgo distintivo de algunos de estos camélidos, exclusivo de la zona, es el abultamiento de sus cuellos como si tuvieran abundancia de pelaje. De hecho, esta misma peculiaridad ha sido observada en el Alto Loa (Berenguer 1999). En todos los casos, los diseños de camélidos son los más abundantes, pero también aparecen acompañados, al menos en un panel grande y abigarrado de representaciones, por un círculo de línea de raspado fino irregular y por cuadrúpedos no determinados de cuerpo lineal o relleno. En cuanto a los camélidos lineales rígidos, éstos son asimilables a los identificados en el Pukara de Turi en sus mismas variantes e inclusive otras, por lo tanto, se consideran manifestaciones contemporáneas al Horizonte Inca como posteriores, configurando la expresión rupestre clásica del Período Tardío.

Aproximadamente $50 \mathrm{~m}$ al sur de estos paneles se localiza un gran pique minero, junto a una serie de socavones menores los que suman alrededor de cinco, presentando restos de escoria como resultado de su explotación. Uno de ellos parece una gran cueva que ha sido cerrada por una pirca y aparentemente utilizada como corral, pues en su interior presenta abundante guano, al mismo tiempo que una densa capa de hollín en el techo y fondo de la cueva, sobre y bajo la cual aparecen pictografías. Las pinturas que están ejecutadas sobre la capa de hollín corresponden a una cruz concéntrica de tres colores, blanco-negro-rojo, y al menos un camélido de trazado más bien rígido pintado en blanco que en términos estilísticos, si bien no técnicos, se asemeja a los de Turi. Bajo la capa de hollín, en cambio, sólo se alcanzan a distinguir restos de pinturas de estilos pertenecientes a épocas más tempranas, específicamente, al estilo Cueva Blanca (Gallardo 1997 Ms y 1999). Asimismo, unos cuantos metros al sur de la cueva se perciben en la pared rocosa lo que podrían ser representaciones humanas en rojo del estilo Confluencia, igualmente temprano (Gallardo $1997 \mathrm{Ms}$ y 1999). Siguiendo hacia el sureste de Cerro Verde, se encuentra un sitio de características habitacionales con estructuras rectangulares y otras de patrón constructivo tipo chullpa que delatan su pertenencia al Intermedio Tardío. Sin embargo, al menos tres de los paneles con arte rupestre que se asocian al sitio El Mirador, como se le ha denominado, dan cuenta de representaciones tardías. 
Casi todos se concentran en un sector del farellón de la quebrada, limitado por un recinto, y otro en un bloque aislado. Nuevamente, se trata de camélidos grabados de tipo rígido y con el cuerpo raspado, e incluso en un caso los mismos aparecen pintados en rojo formando una hilera. Dentro de los grabados, dos con el cuerpo relleno aparecen junto a figuras antropomorfas bastante esquemáticas y también grabadas que se acercan a los "caravaneros" de la fase Santa Bárbara definida para el Alto Loa, pero bastante más simplificados (Berenguer et al. 1985) (Figura 2). Esto se debe a que los personajes no llevan vestimentas ni escudos aunque sí apéndices radiales en la cabeza. Otras expresiones semejantes se internan por las quebradas aledañas a Cerro Verde, a veces combinadas con representaciones más naturalistas de los mismos camélidos, en general, de épocas tempranas (Gallardo 1997 Ms y 1999, Miranda y Saavedra 1995).

En este sentido, destacamos el sitio La Cruz en el curso mismo del río Caspana, correspondiente exclusivamente al tipo de manifestaciones rupestres señaladas como tardías (Figura 3). Este se localiza a unos dos kilómetros aguas arriba del sitio anterior, pero conformando parte de la órbita de distribución de su arte. Se trata de un bloque errático desprendido de la pared de la quebrada y que ahora descansa sobre la margen Este del río. Sólo una de sus caras presenta una pátina negra, la superior y más extensa, siendo la que justamente se ha intervenido exclusivamente con grabados. El bloque se fracturó con posterioridad a dicha intervención, lo cual genera cuatro paneles o subpaneles. El mayor, correspondiente al fragmento más grande o bloque principal, presenta una considerable cantidad de camélidos rectilíneos rígidos de tamaño variable, la mayoría de las veces con sus orejas marcadamente hacia delante tal como ocurre en Turi. También es usual encontrar uno grande con otro de menor tamaño bajo él y orientado en sentido contrario al más puro estilo de la constelación de nube oscura yakana, según las observaciones astronómicas andinas (Berenguer y Martínez 1986), excepto que en esta ocasión el camélido menor o cría no aparece invertido. En este mismo panel aparecen cruces de aspecto similar a la pintada en la Cueva de Cerro Verde, en este caso algunas con círculos interiores y siempre grabadas. Otro elemento interesan- te lo constituye la presencia de al menos dos figuras antropomorfas esquemáticas cuyas cabezas tienen un aspecto similar al cuchillo con forma de medialuna conocido como tumi. Por último, se observan círculos simples y concéntricos, los que en este caso se caracterizan por alternar anillos de raspado lineal con otros de raspado areal.

Un segundo panel presenta los mismos camélidos lineales y rígidos anteriormente descritos a los que se suma una figura antropomorfa bastante esquemática, con apéndices cefálicos y portando una especie de báculo, bastón o lanza en su brazo izquierdo, así como una figura novedosa correspondiente a un felino. La construcción de éste está hecha sobre la base de un reticulado que da forma al cuerpo y cola de un animal cuadrúpedo, además presenta pequeños círculos íntegramente raspados que lo hacen parecer moteado, logrando el aspecto de la piel del "jaguar." Finalmente, en el resto de los paneles se mantienen los camélidos rectilíneos rígidos, algunos con orejas hacia atrás, aparecen muchos círculos concéntricos, sólo lineales, u otros simples y pequeños, así como al menos un personaje más. Sin duda, todo el conjunto representa una de las máximas expresiones del arte rupestre que se configura a partir de $\mathrm{Ce}$ rro Verde.

Subiendo por la quebrada del Caspana, varios kilómetros aguas arriba del actual poblado y cerca de la cabecera del río, se halla la Cueva del Diablo, un sitio muy parecido a la cueva del anterior, excepto porque no se asocia directamente a una instalación incaica y no presenta otra clase de restos culturales que el arte rupestre mismo. Sin embargo, se trata de un socavón de dimensiones considerables con un pircado y una plataforma en el frente, en una de cuyas paredes se registró un panel pintado en negro (Figura 4). En él se representó una hilera de camélidos rectilíneos rígidos, pero con cuerpo de relleno areal y unidos por líneas diagonales entre el cuarto trasero y el cuello. Además, se asocian a ellos al menos dos personajes como los del Mirador, no obstante, en este caso la representación es mucho más elaborada. Exhiben un rostro propiamente tal, tres apéndices radiados sobre la cabeza que parecen plumas, llevan vestimenta a modo de túnicas decoradas con una especie de " $x$ " rodeada de círculos $y$, uno de ellos, porta un objeto delgado pero corto en una mano. En 







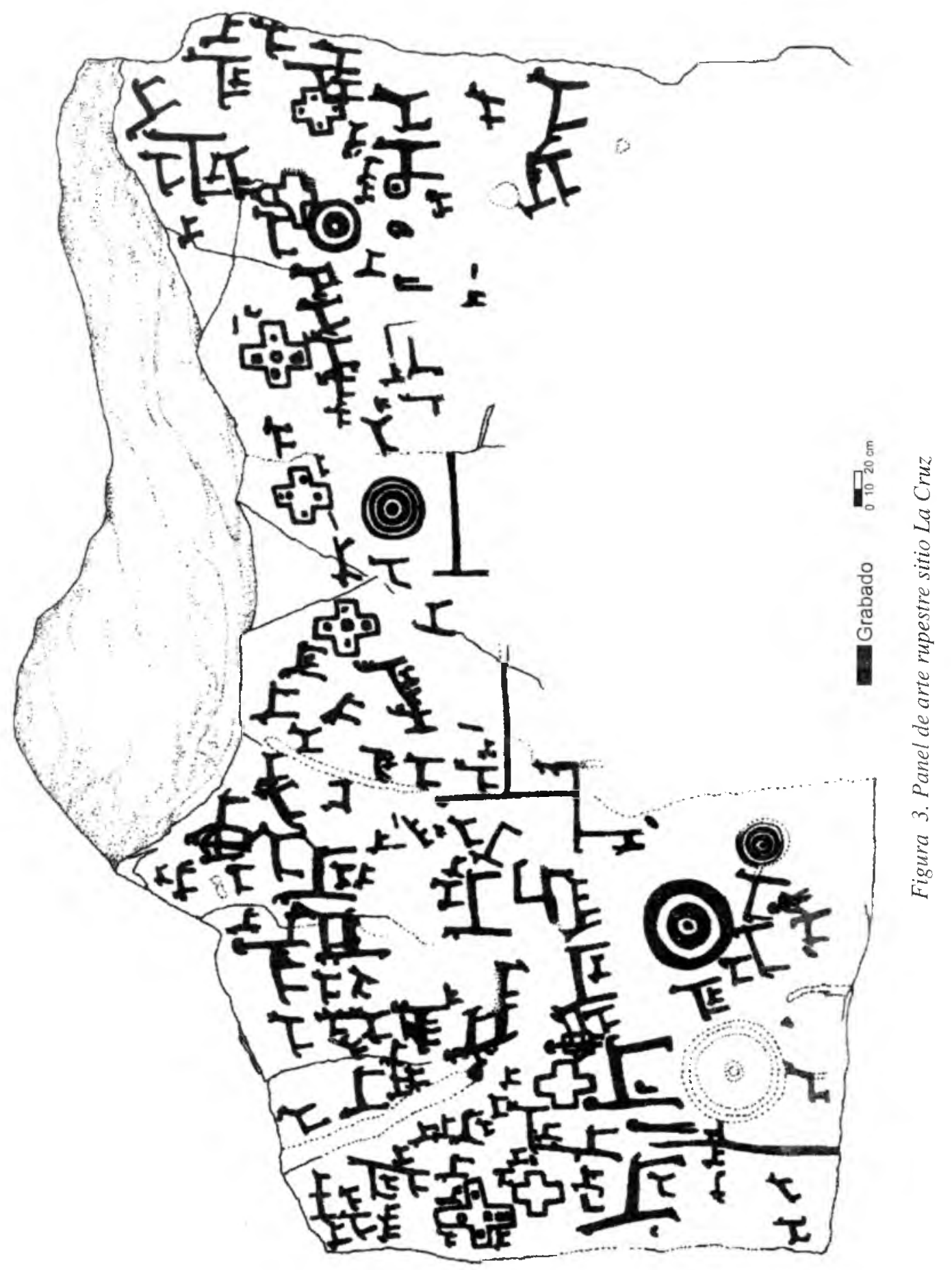




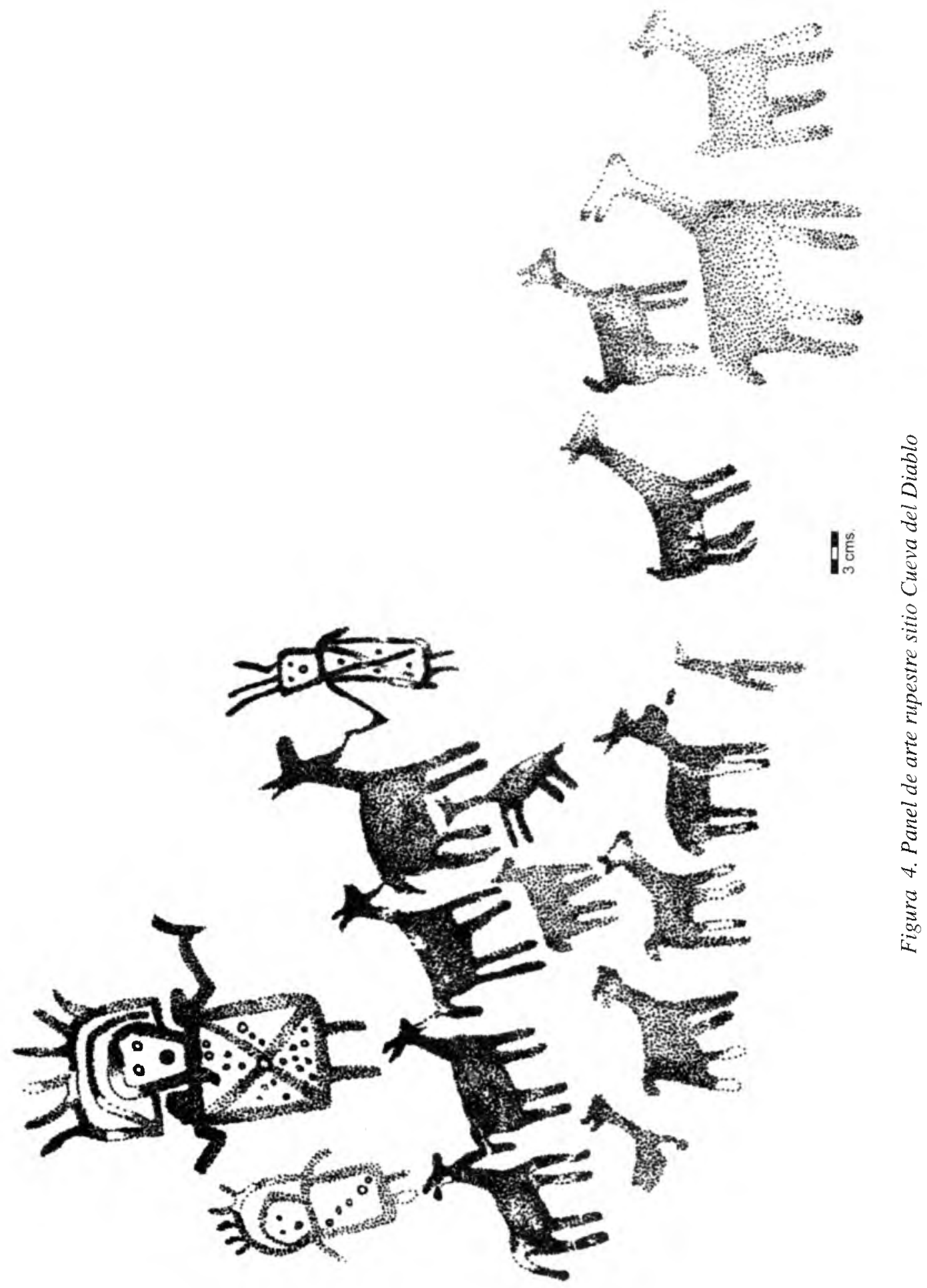




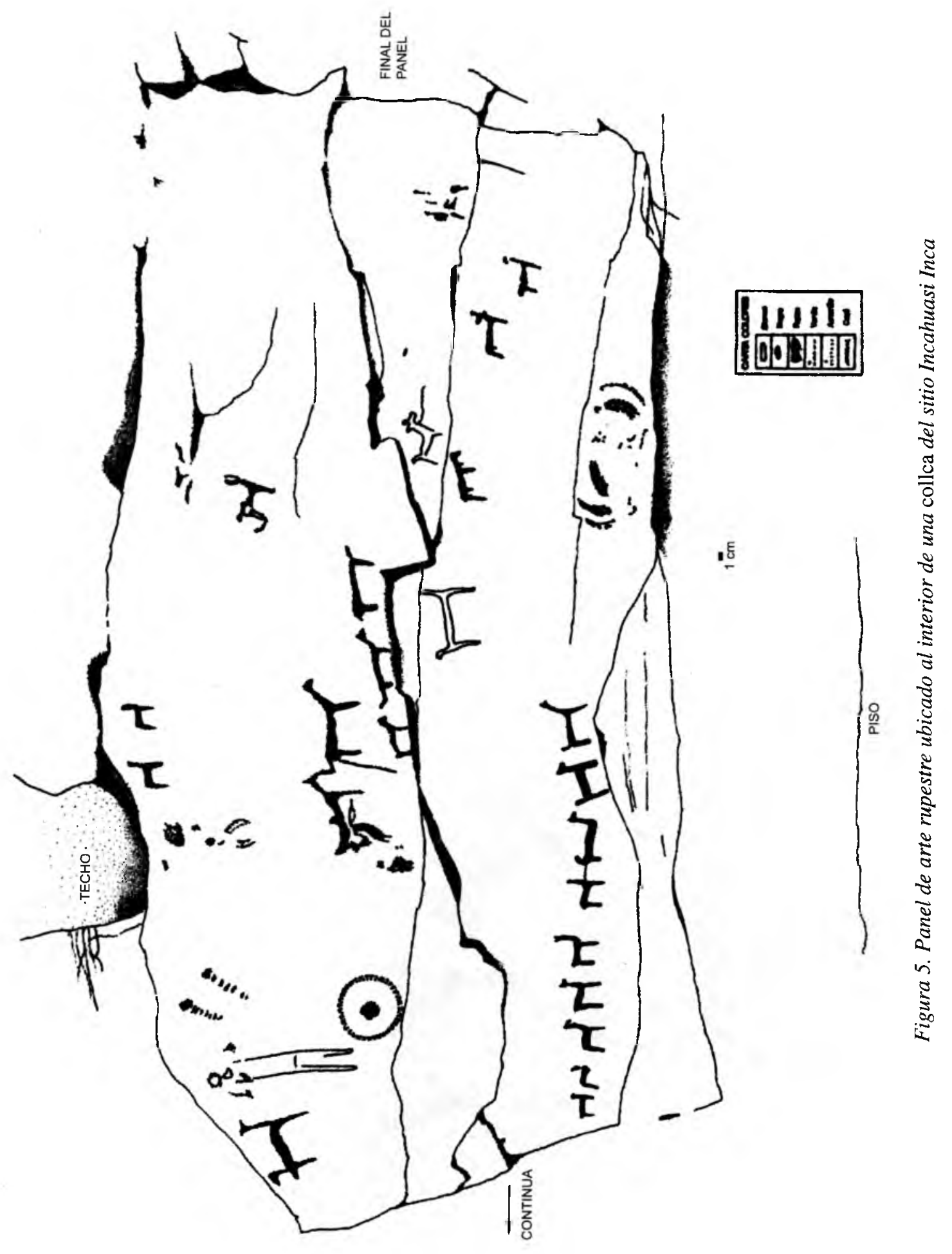


este caso, es indudable su parentesco con los grabados tardíos de Santa Bárbara (Berenguer et al. 1985).

En Incahuasi-Inca, al contrario de los anteriores, el arte rupestre se concentra en el sitio mismo, ni siquiera se le detecta en los alrededores, y comprende sólo manifestaciones pictográficas como en el caso de las cuevas de Cerro Verde y del Diablo. Las representaciones se reparten a lo largo del farellón rocoso cubriendo cerca de cinco metros, aproximadamente, en lo que corresponde a la porción mesial del asentamiento. En total, aquí se contabilizaron unos 15 paneles, muchos de los cuales se encuentran en un estado de conservación deplorable debido a la fuerte exposición solar diaria que reciben en forma directa, a diferencia de otros que se hallan dentro de los depósitos o collcas adosados al farellón. En este contexto se distinguen al menos dos estilos pictóricos regionales y otros indeterminados que en principio estarían dando cuenta de momentos ocupacionales diferentes. El que interesa en este caso, corresponde a los ya clásicos camélidos rectilíneos rígidos propios del Período Tardío, los cuales se encuentran restringidos a un panel, pero pintados en tres colores distintos: negro, rojo y blanco. Conviven e incluso se superponen a otros diseños, algunos seguramente tempranos, no obstante, lo más interesante es su ubicación espacial. Es la única unidad de relevamiento localizada al interior de una collca $\left(\mathrm{N}^{\circ} 8\right)$, quedando oculta al observador que no ingresa a dicha estructura (Figura 5). Más aún, esta elección del espacio interior parece valer sólo para las pinturas tardías, pues el patrón arquitectónico y funcional de las estructuras datan de dicha época. Lo anterior queda absolutamente confirmado por el hecho que uno de los camélidos está pintado con la misma argamasa roja que se usó como mortero para unir las piedras del paramento. En consecuencia, las pinturas más tempranas ya se encontraban presentes en el farellón de la quebrada, pero en la posterior ocupación tardía se cerró dicho espacio mediante construcciones y se crearon nuevas representaciones que deliberadamente fueron inscritas para no ser observadas a simple vista, denotando así una particular conducta de los incas.

Otro importante estilo se identifica en un par de paneles del mismo sitio, cuyo rasgo fundamental son el uso de un rasgo "marco" conformado por líneas onduladas en el que se circunscriben figuras humanas en colores rojo, amarillo y verde. Debido a tales características los diseños se asignan al estilo Cueva Blanca que ha sido ubicado hacia el Período Formativo Tardío (Gallardo 1997 Ms y 1999), es decir, sería arte rupestre temprano a los cuales se unirían varios paneles más aunque ésto no se puede confirmar por el mal estado en que se encuentran. Un tercer estilo es difícil de definir en términos de su asignación cultural y temporal, sin embargo, parece del todo foráneo. Se trata de un par de diseños de un panel con representaciones mixtas por cuanto presentan cuerpo humano, pero caras con hocico, ya que sus bocas se proyectan exageradamente de modo rectangular. Además, llevan objetos alargados en sus manos y parecen estar en desplazamiento. Tales figuras fueron pintadas en blanco, así como otras cuatro representaciones todavía más indeterminables, pero que preliminarmente igual podrían ser incluidas dentro del estilo. Con todo, las características de los personajes recuerdan la iconografía de la cultura Aguada (González, A.R. 1961-64, 1972, 1977), un desarrollo del Período Medio del Noroeste Argentino que se encuentra representado en otros soportes dentro del desierto de Atacama, en especial, en San Pedro a través de textiles y cestería (Berenguer 1984, Pérez 1992). En este sentido, el sitio comprendería incluso manifestaciones de dicho período (Uribe y Carrasco en este mismo volumen). Pero además, existe una serie de al menos cinco paneles que prácticamente han sido imposibles de definir, en su mayoría representados por figuras geométricas aunque, en general, se encuentran muy mal conservados.

A diferencia de las concentraciones de arte rupestre en los alrededores de Cerro Verde y en el sitio mismo de Incahuasi-Inca, en Vega Salada, la tercera de las instalaciones incaicas estudiadas, éste casi no se detecta. No se registraron dichas expresiones en el yacimiento ni en sus alrededores inmediatos, ya que la única muestra procede de un alero rocoso, aparentemente utilizado como corral, situado unos $50 \mathrm{~m}$ aguas abajo del hoy abandonado centro minero San Santiago, es decir, a medio kilómetro al norte de Vega Salada. Con todo, no parece existir una relación directa del arte rupestre con la instalación, ya que éste corresponde a una pictografía de características no conoci- 
das para el período en cuestión. Se trata de una figura con forma de " $x$ " de color rojo con extremos en espiral y delineada por un fino trazo ocreamarillo que, aún cuando también se reconoce en el Alto Loa (Berenguer et al. 1985), dicho motivo todavía no ha sido incluido dentro de las proposiciones cronológicas ofrecidas para este territorio. En cualquier caso, recuerda expresiones tempranas.

\section{Observaciones en torno a la producción y dis- tribución del arte rupestre en Caspana}

De acuerdo a lo revisado en dicha localidad, el universo representacional rupestre que tentativamente corresponde al Período Tardío y, en consecuencia, al Horizonte Inca, comprende principalmente camélidos de tipo lineal y rígido, así como diseños geométricos específicos asociados a ellos. Dentro de los camélidos, al mismo tiempo, es posible reconocer al menos dos tipos compartidos con sitios de otras localidades como el Pukara de Turi, pero además aquí aparecen algunas variantes que complementan la anterior tipología de aquel sitio (Gallardo y Vilches 1995). En primer lugar, se encuentran los camélidos cuyas formas (cuerpo, cabeza, cola, oreja y extremidades), están construidas mediante líneas rectas produciendo un claro efecto de rigidez y esquematicidad (Tipo 1), unas por medio de grabado y otras con pintura (Tipos 1.a y 1.b). En este sentido, las dos variantes se distinguirían por la técnica utilizada aunque ambas pertenecerían al mencionado Horizonte. Por otro lado, se encuentran camélidos cuyas formas están construidas mediante áreas cercanas a cuerpos geométricos regulares aunque producirían en la mayoría de los casos el mismo efecto de rigidez y esquematicidad del tipo anterior (Tipo 2). Sin embargo, aquí se reconocen tres variantes correspondientes al grabado por raspado areal, la pintura areal y el pictograbado con "cuello abultado" (Tipos 2.a, 2.b y 2.c). Dichas variantes, por lo tanto, también se distinguen por las técnicas más que por el diseño mismo, no obstante, la primera de ellas pertenecería a un momento indígena-colonial temprano de acuerdo a las analogías derivadas del Pukara de Turi (Gallardo y Vilches 1995).

Por asociación con estas clases de representación de los camélidos, se ha detectado una serie de motivos contemporáneos con aquellos claramente adscribibles al Horizonte Inca, casi todos los cuales fueron elaborados con la técnica de grabado. Entre ellos destacan los círculos simples o de un solo anillo, los concéntricos con diversos modos de surcos, los puntos que son círculos completamente rellenos por raspado, las cruces concéntricas y/o con círculos interiores y las figuras antropomorfas esquemáticas, por lo general, con cabeza "tumiforme" $o$ apéndices cefálicos con forma de medialuna y también radiados, portan objetos en las manos y a veces están en directa relación con hileras de camélidos a modo de caravanas (Cerro Verde y Cueva del Diablo).

Al contrario, en los asentamientos de innegable origen local y consecuentemente previos a la expansión del Tawantinsuyu, sólo se identificaron manifestaciones "menores" de este arte, cuyo estilo se asemeja muy poco a aquel que se inserta o circunda las instalaciones del Inca como hemos visto en Talikuna. Lo anterior, en cualquier caso, contrasta y extraña frente a una larga tradición local que ha venido reproduciendo la imagen del camélido por miles de años en este territorio, denotando el tremendo valor simbólico de este animal para sus habitantes (Berenguer 1999, Gallardo 1999).

Respecto a la producción y distribución de este arte, en primer lugar, proponemos que la representación del camélido tal cual ha sido descrita en este estudio, es el resultado de la expansión del Tawantinsuyu (Berenguer 1995, Cáceres y Berenguer 1996). Esto, porque pareciera que el Inca favorece sus instalaciones para el despliegue de este estilo en todas sus posibilidades técnicas y con ello, al menos en Caspana, muestra un interés por asentarse directa o indirectamente en lugares ocupados por grupos de momentos previos al Intermedio Tardío o tempranos, por cuanto pudieron ser de épocas arcaicas o formativas. De hecho, como apoyo a lo anterior, en varios de estos sitios se ha registrado alfarería de aquel último momento. En consecuencia, y muy de primera mano, pareciera que el Inca se está instalando en lugares ocupados previamente por grupos tempranos como los sugieren Incahuasi-Inca y la Cueva de Cerro Verde, al mismo tiempo que fuera de los asentamientos locales tardíos (Uribe et al. 2000). 
Especialmente, por otro lado, en tales casos esta "retraducción" en cuanto a la ocupación de los lugares resulta doblemente significativa puesto que además ocurre dentro del mismo dominio. Esto se refiere, a pesar de la variación de las formas y de la absoluta preeminencia del grabado, que se repite la técnica de la pintura conocida desde antiguo por los locales (Gallardo 1997 Ms y 1999). Respecto a lo anterior, tampoco deja de ser significativo el que no se trate de un acto violento pues, en efecto, no se detectan superposiciones radicales ni borrones, al contrario, las pinturas conviven compartiendo el mismo soporte rocoso. Desde el punto de vista tecnológico, podríamos incluso sugerir que la selección de pintura para dibujar este tipo de camélidos es menos agresiva que la técnica del grabado, ya que evidentemente este último implica una marca indeleble, no así la pintura. Otra cualidad de la técnica pictórica es que permite la introducción e interacción de diversos colores, que en estos dos sitios corresponden al rojo, blanco y negro. Por otro lado, la reutilización de un mismo soporte señala su importancia como lugar --sagrado tal vez--, sea en términos de entorno (confluencia y cabeceras de ríos), accesibilidad a recursos o localización estratégica (andenes de cultivo, zonas de pastoreo y minas), entre muchos otros. Finalmente, ya sea por casualidad o no, dentro de nuestra muestra existen tres casos donde el arte rupestre se limita exclusivamente a pinturas (Cueva de Cerro Verde, del Diablo e IncahuasiInca), a veces policromas, independientemente de su variabilidad estilística y cronológica, demostrando así la importancia de aquellas.

Más particularmente todavía, es el caso de Incahuasi-Inca que es el único asentamiento o instalación con propiedad que tiene arte rupestre in situ. Con todo, es extraño que aquí el arte rupestre incaico haya sido ocultado, sin embargo, el anterior sigue estando a la vista de una forma protagónica.

En cambio, ¿hasta qué punto se pueden considerar los camélidos de Cerro Verde y las representaciones asociados a ellos como parte misma del sitio? Si lo fueran sería un dato importante, porque se trataría de tres ocupaciones del Tawantinsuyu --el Pukara de Turi, Incahuasi-Inca y Cerro Verde--, con esta "marca imperial" representada por los camélidos lineales y rígidos. Más aún, estos ante- cedentes indicarían que este estilo de iconografía rupestre no sólo se restringe a sitios no-habitacionales destinados a marcar áreas de importancia económica para la crianza y mantenimiento de los animales (rocas aisladas, cuevas, etc.), como González y colaboradores ( 1997 Ms) lo sugieren. En realidad lo que se aprecia son dos situaciones, en ningún caso excluyentes. Por un lado, el diseño camélido efectivamente actúa como una marca territorial en sitios no-habitacionales gracias a sus propiedades formales altamente estandarizadas y reconocibles a lo largo del imperio en diferentes dominios de la cultura material incaica. Por el otro, los asentamientos también poseen esta especie de "marca de fábrica", y probablemente la tienen por tratarse de la fábrica misma. Incluso, es justamente en esta clase de sitios donde encontramos exclusivamente los camélidos del tipo 1.b o pintados, además de los grabados (Cerro Verde e IncahuasiInca).

Entonces, pareciera que la técnica, sumada a la forma, añaden una nueva arista significativa que fija la importancia del asentamiento más allá de la economía. Al mismo tiempo, en este contexto se inserta la relevancia de las mismas representaciones, pero grabadas, ya que se trata de la marca indeleble, la cual sería especialmente desplegada en torno a las instalaciones más exclusivas como Cerro Verde y Turi donde el Estado se concentra y manifiesta en forma pública sin mayores reservas su fortaleza.

En consecuencia, no es en todos los asentamientos donde se representa esta imagen, sino en aquellos particularmente ligados al Inca, puesto que en Talikuna como en otros sitios de la población local, por ejemplo en Mulorojte, su manifestación es prácticamente nula.

\section{Reflexiones sobre el arte rupestre del Período Tardío}

Tal cual lo señalara Hyslop (1990), la arquitectura inca imperial no se destaca por la ornamentación de sus edificaciones. Cuando mucho ésta se reduce a jambas y aperturas en los muros, rasgos que paralelamente cumplen roles funcionales $y / o$ estructurales, así como a muros estucados y luego pintados en negro, rojo, blanco y amarillo, o bien adornados con placas de metal. De hecho, los re- 
gistros de grabados de animales pequeños o patrones geométricos simples, son muy escasos dentro de la órbita cuzqueña y, más aún, "their depiction may have increased in Inca masonry laid in early Spanish times" (Hyslop 1990: 11). Bajo esta perspectiva, todo indica que la ornamentación incaica imperial más tenía que ver con la selección de un paisaje concreto, generalmente compuesto por grandes afloramientos rocosos en estado natural o intervenidos mediante grabados (p.e. Kenqo, Saqsawamán, Sayhuite), que pasaban a integrar activamente el trazado arquitectónico. Asimismo, este paisaje era usualmente "remodelado" a través de la construcción de terrazas, nichos, canales, fuentes y èstanques de agua (Hyslop 1990).

Fuera del centro del Tawantinsuyu, pareciera que la mayoría de los registros estrictamente artísticos del Período Tardío (pinturas y grabados sobre roca o tierra) provienen de Bolivia, Chile y Argentina. En efecto, conocemos estructuras del tipo chullpa del pueblo de Caquiaviri, al suroeste de La Paz, así como del área Lupaca, que presentan decoración exterior y/o interior pintada o esculpida (Pärssinen 1993: 9-32). Especial interés nos merecen las primeras, ya que en los muros interiores de un par de ellas aparecen pinturas de camélidos pequeños, similares al tipo 1.b de Caspana (Pärssinen 1993: fig. 1.4.3). La técnica de grabar grandes afloramientos de roca o pequeños bloques móviles, en cambio, tiene antecedentes que cubren casi todo el imperio y que no siempre se encuentra asociada a sitios habitacionales (Hyslop 1990). De hecho, maquetas propiamente tales, aparecen desde el Ecuador hasta la zona de quebradas altas de la cuenca del río Loa en Chile como Quebrada Seca, Patillón y Lasana (Gallardo 1999) y, de alguna manera, en las manifestaciones rupestres registradas en la Aldea Talikuna donde la roca sufre intervenciones literalmente profundas que comparten cierto aire de familia.

Con todo, lo importante aquí es señalar que el arte rupestre propiamente tal, excluyendo el fenómeno "maquetas", parece ser una manifestación artística que se desarrolla intensamente en la porción meridional del imperio. De hecho, camélidos del tipo 1.a o rectilíneos rígidos grabados, el más popular la región de estudio, aparecen profusamente en el río Salado, afluente del Loa
(González et al. 1997 Ms), en el Valle Calchaquí del Noroeste argentino (Lanza 1997 Ms) y probablemente en muchas otras regiones aledañas que ahora escapan a nuestros registros como el estudio de Albarracín-Jordán. Más interesante incluso es el hecho de que, pese a tratarse de un diseño iconografico "oficial" cuzqueño, propio de los dominios textil, cerámico y metalúrgico, el soporte roca es exclusivo de esta periferia. Siguiendo a Hyslop (1993: 337), "The variations in the material remains are crucial, because, if we understand what has caused them, we learn great more not only about Incas, but about the people they ruled". $\mathrm{Y}$ lo que por ahora podemos aprender de las poblaciones locales de este territorio es que, a través de la representación de camélidos lineales rígidos, por ejemplo, dejan en claro que el poder simbólico de dicha imagen va más allá de la naturaleza del soporte y de la distribución artefactual a grandes distancias como parte de circuitos económicos mayores como el caravaneo. En ese sentido, también sospechamos que el cambio de soporte obedece a una necesidad local de compensar, sustituir o reemplazar la ausencia de los soportes clásicos para el diseño en cuestión. A ese respecto, los estudios de la cerámica encontrada en los asentamientos aquí informados hablan por sí mismos (Adán y Uribe 1999, Uribe 1999, Uribe et al. 2000).

Por último, y a raíz del sitio Incahuasi-Inca, es interesante observar la posibilidad de que la amplia variabilidad detectada en el registro cerámico que da cuenta de un permanente contacto con el Noroeste Argentino, entre otras zonas, quede refrendado con el posible nexo con la cultura Aguada que aquí se ha sugerido. De ser así, la presencia de iconografía propia del Período Medio indicaría que en esta localidad específica, los circuitos de movilidad al otro lado de los Andes funcionaban con anterioridad al Período Tardío y, probablemente, facilitaron su posterior eficiencia durante la instalación del Inca. Bajo esa perspectiva, la circulación de representaciones rupestres similares entre una y otra vertiente cordillerana nuevamente hablan de la fuerza simbólica de determinadas imágenes, por más largas que sean las distancias y más distintos los patrones de subsistencia.

Evidentemente, queda mucho por investigar en 
torno al tema del arte rupestre tardío, y más aún, en torno a la iconografía circulante durante tiempos incaicos. Sería necesario en un futuro llegar a determinar el componente "local" y "oficial" de ese circulante, así como los circuitos, áreas de distribución y alcance de los mismos.

No obstante, ya se sabe que existe una proporción considerable de representaciones parietales asignables al período en cuestión, en distintos sectores de la región como alrededor de los sitios mismos, en el contexto de una práctica conocida y manejada desde antiguo por la población local. En este sentido, ella se convierte en un "emblema" de la presencia del Tawantinsuyu del mismo modo que en Bolivia, Argentina y parte del Norte Grande del país. Estas representaciones, hoy denominadas estilo Quebrada Seca (Gallardo 1999), comprenden principalmente camélidos de tipo rectilíneo, acompañados por un número menor de figuras geométricas y humanas, todas ellas elaboradas en diversas técnicas y emplazadas en distintos lugares, aún cuando el soporte siempre es rocoso. Los animales están construidos mediante líneas rectas produciendo un claro efecto de rigidez y esquematicidad, unos grabados con surco fino y otros pintados en colores blanco, negro o rojo. Algunos, tal vez más tardíos, fueron hechos mediante áreas cercanas a cuerpos geométricos regulares, pero igualmente rígidos, esquemáticos, grabados, pintados e incluso pictograbados (amarillo). Muchas veces forman verdaderas hileras, en ocasiones unidos a la altura del cuello y el lomo por una línea diagonal, por lo cual han sido interpretadas como caravanas de llamas. En otros casos, se representan camélidos pequeños bajo otros grandes a modo de yakana. Asociados a ellos aparecen intercaladas las figuras geométricas en su mayoría grabadas, pero también pintadas, correspondientes a puntos, anillos simples, concéntricos y cruces de lados iguales con círculos. Asimismo, junto a algunos, en especial los que forman caravanas, se encuentran figuras antropomorfas esquemáticas con tocados en la cabeza entre los que destacan adornos con forma de medialuna o radiados, tanto grabados como pintados. Pero además, aparece otra expresión de arte rupestre incaico, incluso en un caso asociada a la anterior, correspondiente a las maquetas hechas en gran- des bloques de piedra que reproducen una verdadera escultura de lo que parecieran ser las terrazas de cultivo y sus canales a través de intervenciones profundas sobre la roca (Gallardo 1999).

En suma, más allá de su calidad y cantidad, a partir de todas estas expresiones artísticas se advierte el patrón estético imperial, en primer lugar, porque éste tenía que ver con la selección de los paisajes que generalmente privilegiaron notables afloramientos rocosos, así como cierta clase de oquedades en ellos a modo de aleros, piques y cuevas. Y, por otro lado, se advierte dicho patrón debido a la utilización de un motivo altamente simbólico para el Estado como fueron los camélidos (Vilches 1999). Por lo mismo, no es de extrañar que en la localidad de Caspana este arte se localice en tales accidentes como son las cuevas o piques y bloques erráticos de los alrededores de Cerro Verde, en la quebrada misma del río Caspana y en el alero de Incahuasi-Inca los que parecen haber sido considerados y convertidos en verdaderas huacas al modo de los cusqueños. Esta situación se repite en las nacientes del Loa y el Noroeste argentino (Berenguer 1999, Aschero 1999). Y no por casualidad, los camélidos representados aparecen asociados a recursos de agua, campos de cultivo, pastoreo y minas. A esto se suma, su ejecución en sitios ocupados por estilos generalmente anteriores, por lo cual pueden ser adscritos a la categoría de lugares antiguos los que también pasaban a formar parte de las prácticas religiosas del Tawantinsuyu. Pero, al mismo tiempo, siempre dentro de un dominio que pareciera ser propio de gran parte de la porción meridional del imperio, el Collasuyu, a la cual pertenecerían estos territorios.

Todo esto en conjunto nos sugiere no sólo la apropiación simbólica del paisaje natural y cultural de las quebradas afluentes del Loa Superior por parte del Inca (Uribe et al. 2000), sino también la integración de su población a la construcción del Tawantinsuyu, lo que de algún modo se sigue reproduciendo en la actualidad. Por ejemplo, en el culto a los cerros; aún hoy las comunidades indígenas asocian al Inca y a sus restos al agua y la riqueza (Manríquez en este volumen, Uribe et al. 2000, Vilches 1999). 


\section{BIBLIOGRAFIA}

ADAN, L., y M. URIBE. El Inca en la localidad de Caspana: 1999 Un acercamiento al pensamiento político andino (Río Loa, Norte de Chile). Enviado a Tawantinsuyu, Sidney.

ASCHERO, C. $\quad$ El arte rupestre del desierto puneño y el 1999 Noroeste Argentino. Arte rupestre en los Andes de Capricornio, pp. 97-135, Museo Chileno de Arte Precolombino, Santiago.

BERENGUER, J. Hallazgos La Agüada en San Pedro de 1984 Atacama. Gaceta Arqueológica Andina 12:12-14, Lima.

1995 Caravaneo prehispánico tardío y cambio cultural en Santa Bárbara, Alto Loa: El lugar como proceso. Hombre y Desierto Tomo 1 (9):185-202, Antofagasta.

1999 El evanescente lenguaje del arte rupestre en los Andes atacameños. Arte rupestre en los Andes de Capricornio, pp. 9-56, Museo Chileno de Arte Precolombino, Santiago.

BERENGUER, J., y J.L. MARTINEZ. El río Loa, el arte ru1986 pestre de Taira y el mito de Yakana. Boletín del Museo Chileno de Arte Precolombino 1:79-99, Santiago.

BERENGUER, J., V. CASTRO, C. ALDUNATE, C. SIN1985 CLAIRE y L. CORNEJO. Secuencia de arte rupestre en el Alto Loa: Una hipótesis de trabajo. Estudios en arte rupestre, C. Aldunate, V. Castro y J Berenguer (Eds.), pp. 87-108, Museo Chileno de Arte Precolombino, Santiago.

CACERES, I., y J. BERENGUER. El caserío de Santa Bárba1996 ra 41, su relación con la w'aka de Taira, Alto Loa. Chungara 28:1-2, Arica.

GALLARDO, F. Un estilo de arte rupestre en la subregión $1997 \mathrm{Ms}$ del río Salado (II Región). Informe Proyeeto FONDECYT 1950101, Santiago.

1999 Arte rupestre, emplazamiento y paisaje en la cordillera del desierto de Atacama. Arte rupestre en los Andes de Capricornio, pp. 57-96, Museo Chileno de Arte Precolombino, Santiago.
GALLARDO, F., y F. VILCHES. Nota acerca de los estilos de 1995 arte rupestre en el Pukara de Turi (Norte de Chile). Boletín de la Sociedad Chilena de Arqueología 20:26-28, Santiago.

GONZALEZ, A.R. La cultura de la Aguada del N.O. Ar1961-1964 gentino. Revista del Instituto de Antropología Tomo II-III, pp. 203-253, Córdoba.

1972 The felinic complex in Northwest Argentina. The cult of the feline, A Conference in Pre Columbian Iconography, Dumbarton Oaks Research, pp. 133-202, Library and Collections, Washington.

1977 Arte precolombino de la Argentina. Editorial Filmediciones Valero, Buenos Aires.

GONZALEZ, J., P. AYALA, F. GALLARDO y F. VILCHES 1997 Ms Representaciones de camélidos en el arte rupestre de la cuenca del río Salado (II Región-Chile). Ponencia presentada al Congreso Internacional de Cochabamba, Cochabamba.

HYSLOP, J. Inca settlement planning. University 1990 of Texas Press, Austin.

1993 Factors influencing the transmission and distribution of Inca cultural materials throughout Tawantinsuyu. Latin American Horizons, pp. 337-356. A Symposium at Dumbarton Oaks, Dumbarton Oaks Research Library and Collections, Washington D.C.

LANZA, M. Análisis temático en el arte rupestre 1997 Ms del valle Calchaquí norte (Salta, Argentina). Resumen de ponencia presentada al Congreso Internacional de Cochabamba, Cochabamba.

LE PAIGE, G. Antiguas culturas atacameñas en la cor1958 dillera chilena (II parte). Anales de la Universidad del Norte 4:3-29, Antofagasta

MIRANDA, P., y M. SAAVEDRA. De como caminamos 30 1995 días por las tierras de Caspana, de las 
cosas que hicimos y las maravillas que allí vimos. Boletín de la Sociedad Chilena de Arqueología 20:29-30, Santiago.

PÄRSSINEN, M. Torres funerarias decoradas en Caquia1993 viri. Revista Pumapunku 2: 5-6, La Paz.

PEREZ, J. $\quad$ Los sueños del jaguar. Viaje a la región 1992 de la sabiduría y de los señores iluminados. Sueños del jaguar. Imágenes de la selva y la puna argentina, Museo Chileno de Arte Precolombino, Santiago.
URIBE, M. La alfarería inca de Caspana (Norte de 1999 Chile). Boletín de la Sociedad Chilena de Arqueología 27:1 1-19, Santiago.

URIBE, M., V. MANRIQUEZ y L. ADAN. El poder del Inca 2000 en Chile: Aproximaciones a partir de la arqueología de Caspana (Río Loa, Desierto de Atacama). Actas del III Congreso Chileno de Antropología, pp. 706-722, Lom Ediciones, Santiago.

VILCHES, F. Inca rock art?: minor arts, major 1999 meanings. Thesis for the degree of Master of Arts. University of Maryland, Washington. 
